\title{
Effect of Environmental Impact in Building Constructions
}

\author{
Md. Masud Rana ${ }^{1}$, Md. Samdani Azad ${ }^{2}$, Atika Hossain Akhi ${ }^{3}$, Gazi Md. Sharfaraz Imam Azad ${ }^{1}$ \\ ${ }^{1}$ Department of Civil Engineering, Rajshahi University of Engineering \&Technology, Rajshahi, Bangladesh \\ ${ }^{2}$ Department of Civil \& Environmental Engineering, Mahidol University, Nakhon Pathom, Thailand \\ ${ }^{3}$ Department of Civil Engineering, Presidency University, Dhaka, Bangladesh
}

\section{Email address:}

masud.ce08@gmail.com (Md. M. Rana), samdani.civil.ruet@gmail.com (Md. S. Azad), atika2012cen@gmail.com (A. H. Akhi), sharfaraz.azad.civil@gmail.com (G. Md. S. Imam Azad)

\section{To cite this article:}

Md. Masud Rana, Md. Samdani Azad, Atika Hossain Akhi, Gazi Md. Sharfaraz Imam Azad. Effect of Environmental Impact in Building Constructions. American Journal of Civil Engineering. Vol. 5, No. 6, 2017, pp. 339-343. doi: 10.11648/j.ajce.20170506.14

Received: July 31, 2017; Accepted: July 31, 2017; Published: October 30, 2017

\begin{abstract}
This paper deals with the effect of environment in construction work in a particular area. Surrounding environment has immense effect in construction plan, site management, costs and implementation. On the contrary, it affects the workmanship's availability as well as material availability. Moreover, duration of a certain projects also depend on the impact of environment. Effect of climate, rainfall, humidity and temperature are the noticeable fact in the paper. This article represents the environmental effect of a particular place in Rajshahi city of Bangladesh which is known as RUET campus. Outcome of the investigation shows that the significant effect can be observed in the various ingredients of environment as well as construction project.
\end{abstract}

Keywords: RUET, Environmental Impact, Construction, Material

\section{Introduction}

Rajshahi University of Engineering \& Technology (RUET) is the 2nd oldest prestigious higher educational Engineering University in Bangladesh. The institute was founded in 1964 as Rajshahi Engineering College with three faculties and limited number of students. The name of the institute was turn to Bangladesh Institute of Technology (BIT), Rajshahi in 1986 to enhance the technical education and finally it is upgraded as Rajshahi University of Engineering \& Technology (RUET) in 2003 to enhance the technical education and research. The institute first intake students was 122 in 1964 and extended to 3000 plus now including undergraduate and post-graduate program. Number of students, teachers and staffs are increasing. But facilities for accommodation of students, teachers and staff have not been increased harmoniously. To meet the demand RUET needs to provide facilities of accommodation for students, teachers and staffs. Based on the above scenario RUET intends to construct 6 buildings for students, teachers, staffs and guests coming from outside. Among these one for student's accommodation, one for teachers, two for staffs and another one as a guest house will be used. These buildings are located different parts of campus which are shown in site map.

\subsection{Objectives of the Project}

The objectives of the proposed project is to construct buildings for providing accommodation of the increasing students, teachers and staffs of Rajshahi University of Engineering \& Technology (RUET).

\subsection{Objectives of the Eia Study}

Environmental impact assessment (EIA) study of construction of buildings has been carried out.

The EIA study specifically included the following scope of works: Describing the environmental baseline situation of the area;

1. Identifying alternative site and its suitability;

2. Identifying and analyzing the potential environmental impacts, including residual impact of the proposed project

3. Exploring the people's perception on the projects; and

4. Preparing an Environmental Management Plan 
Scope of work

The scopes of work of the present EIA study were as follows.

1. Alternative site analysis and selection of best site;

2. Conduction of environmental baseline survey and select environmental and social components likely to be impacted by the project;

3. Assessment and evaluation of impacts;

4. Preparation of detail Environmental Management Plan (EMP);

5. Preparation of ESIA report; and

6. Presentation of ESIA results to DoE to get 'Environmental Clearance

\section{Description of the Project}

The Construction Works include:

1. Construction of Guest House \& Club up to 2nd Floor

2. Construction of Architecture Building up to 2nd Floor

3. Construction of Bangabandhu Hall up to 2nd Floor

4. Construction of Teachers Quarter up to 3rd Floor

5. Construction of Officers Quarter (Pess Imam's) upto Ground Floor

6. Construction of staff Quarter up to 2nd Floor

The construction works shall be carried out in two phases.

PHASE 1: Demolition of any loose material, clearing and site preparation for new building construction, and

PHASE 2: new building construction The sites are located at different parts of RUET. Guest house and club is located at eastern part of RUET campus, beside the central playground. It comprises 4250 sq. ft. floor area. Architecture Building is located western side of campus and backside of Civil Engineering department along the Talaimari-Vodra road. It will cover 5600 sq. $\mathrm{ft}$. floor area. Bongobondhu Hall is in the middle part of campus area, southern side of Shahid Lt. Selim Hall. It has floor area of $6200 \mathrm{sq}$. ft. Teachers Quarter is situated at the residential area. It has floor area of $2318 \mathrm{sq}$. $\mathrm{ft}$. Officers Quarter is located near the central mosque. It has area of 1150 sq. $\mathrm{ft}$. Staff Quarter is located at northern part of campus having area of 2040 sq. $\mathrm{ft}$.

The scope of the main physical work include the total manufacturing, transport and delivery to the site, installation, execution, completion, testing and handing over of the works being: All civil, architectural and structural works for the project, including clean-up of construct demolition waste (various concrete structures) generated during previous works stored in this space which amount is estimated to be small amount, site preparation, fire escape, new building construction with electrical installation works and emergency power generator; water supply, drainage and sewage works, road pavement and parking, green areas and vegetation, for full completion.

\section{Environmental Baseline Condition}

One of the most important tasks of the EIA was to assess the existing environmental conditions of the project site and its surrounding areas in order to establish a "baseline", against which potential environmental and social impacts due to the implementation of the project would be predicted and assessed. In order to establish the baseline environment, detailed physical, ecological and socioeconomic surveys have been carried out surrounding the project site. This chapter provides a description of the baseline physical, ecological and socio-economic condition of the project area and its surroundings.

\subsection{Land Use}

No crop is produced in the land area of guest house \& club, teacher's quarter, architecture building and bangabandhu hall. Small trees and grasses are seen in this area. The land of officer's quarter is used to grow some fruits and sometimes this land is used for growing some crops. In the staff quarter area land is low lying relative to the other lands. Only one seasonal crops are grown by using rainy water.

\subsection{Atmosphere and Water Resources}

\subsubsection{Climate}

Rajshahi has a tropical wet and dry climate. The climate of Rajshahi is generally marked with monsoons. The hot season commences early in March and continues till the middle of July. The average temperature for the year in Rajshahi is $78.3^{\circ} \mathrm{F}\left(25.7^{\circ} \mathrm{C}\right)$. The warmest month, on average, is June with an average temperature of $85.3^{\circ} \mathrm{F}\left(29.6^{\circ} \mathrm{C}\right)$. The coolest month on average is January, with an average temperature of $64.0^{\circ} \mathrm{F}\left(17.8^{\circ} \mathrm{C}\right)$. (weatherbase. com).

\subsubsection{Rainfall}

The average amount of precipitation for the year in Rajshahi is 60.7" (1541.8 mm). The month with the most precipitation on average is July with 12.6" (320 mm) of precipitation. The month with the least precipitation on average is January with an average of $0.4 "$ (10.2 $\mathrm{mm})$. In terms of liquid precipitation, there are an average of 86.0 days of rain, with the most rain occurring in July with 15.0 days of rain, and the least rain occurring in December with 1.0 days of rain. The rainfall outcome are presented in Figures (1-2).

\subsubsection{Temperature}

The weather base data at Rajshahi at last 30 years in Figures (3-5) shows that the monthly average maximum temperature in months varies from $24^{\circ} \mathrm{C}$ to $36^{\circ} \mathrm{C}$ while the maximum temperature occurring over the months of March to May is around $36^{\circ} \mathrm{C}$. The monthly average temperature varies from $18^{\circ} \mathrm{C}$ to $29^{\circ} \mathrm{C}$. The monthly minimum temperature ranges from $13^{\circ} \mathrm{C}$ to $26^{\circ} \mathrm{C}$ and the minimum temperature (December to January) is around $13^{\circ} \mathrm{C}$.

\subsubsection{Relative Humidity}

The yearly average relative humidity varies from $72 \%$ to $82 \%$ in last 24 years (1981 to 2007) as shown in the Figure 6. The monthly average relative humidity varies from $35 \%$ to $88 \%$ in last 30 years (Wikipedia). In the summer, Average 
relative humidity varies from $60 \%$ to $72 \%$, in the Monsoon, $81 \%$ to $71 \%$ and in the Winter, it again decreases up to $71 \%$ to $60 \%$ (Figure 6). Due to high level of humidity, the Monsoon, more sweating occurs.

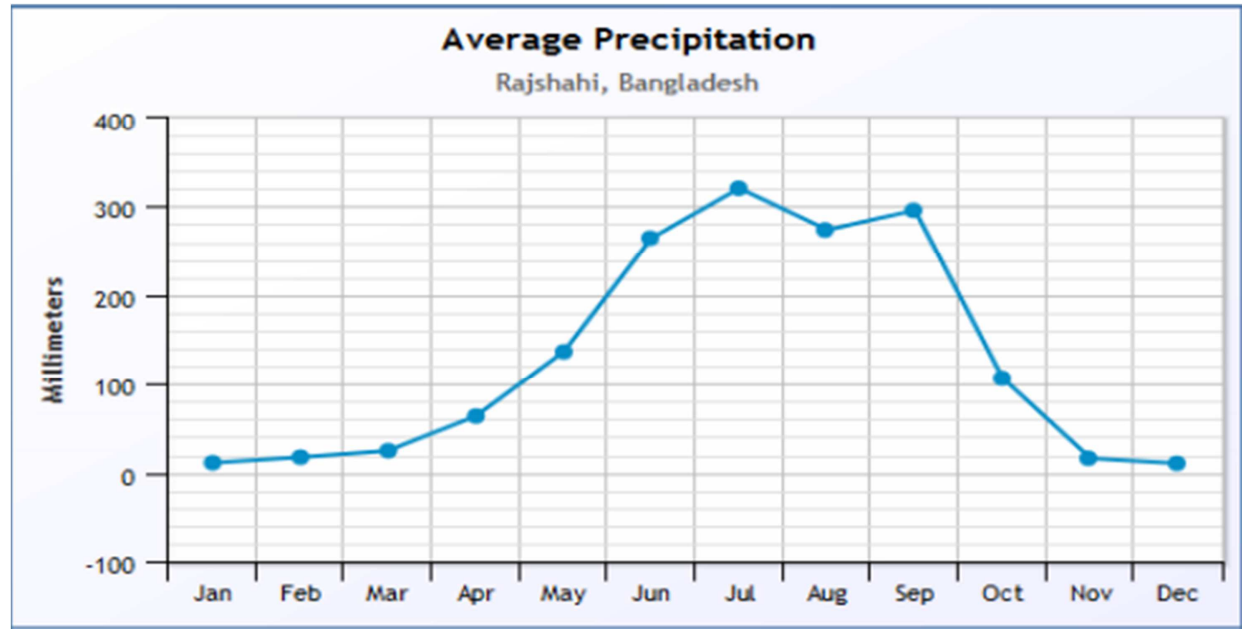

Figure 1. Monthly Average Rainfall of Last 30 Years (Weatherbase.Com)

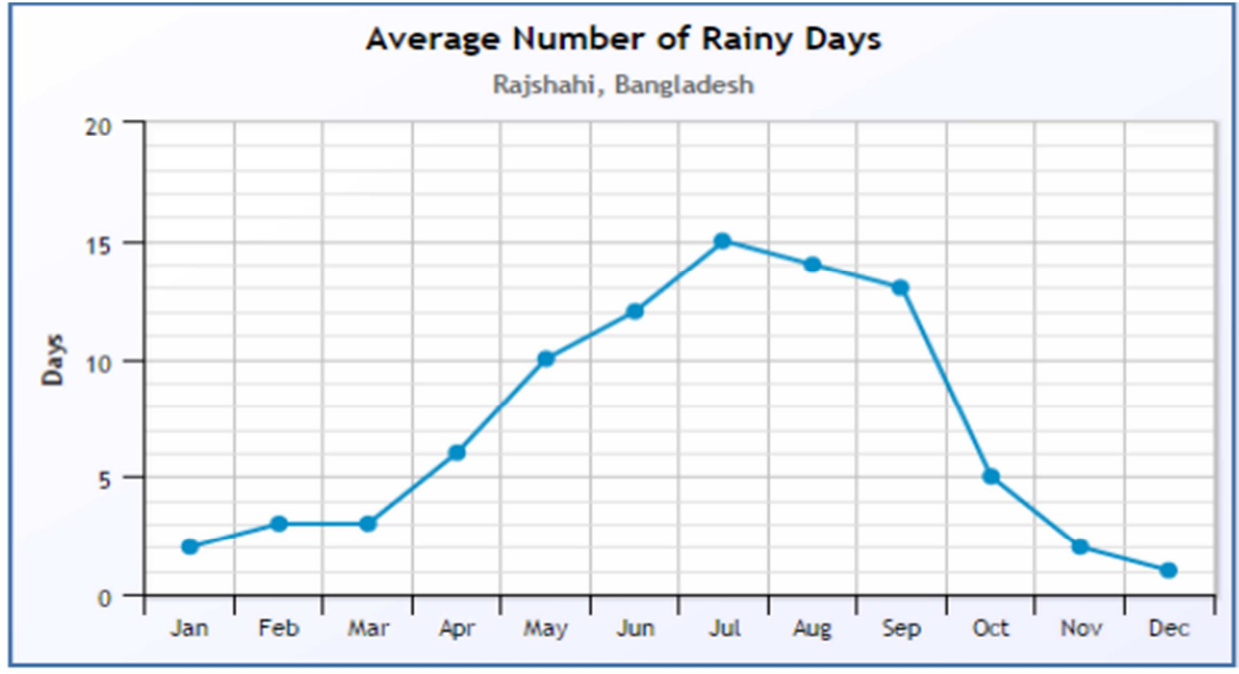

Figure 2. Monthly Average Rainy Day of Last 30 Years (Weatherbase.Com).

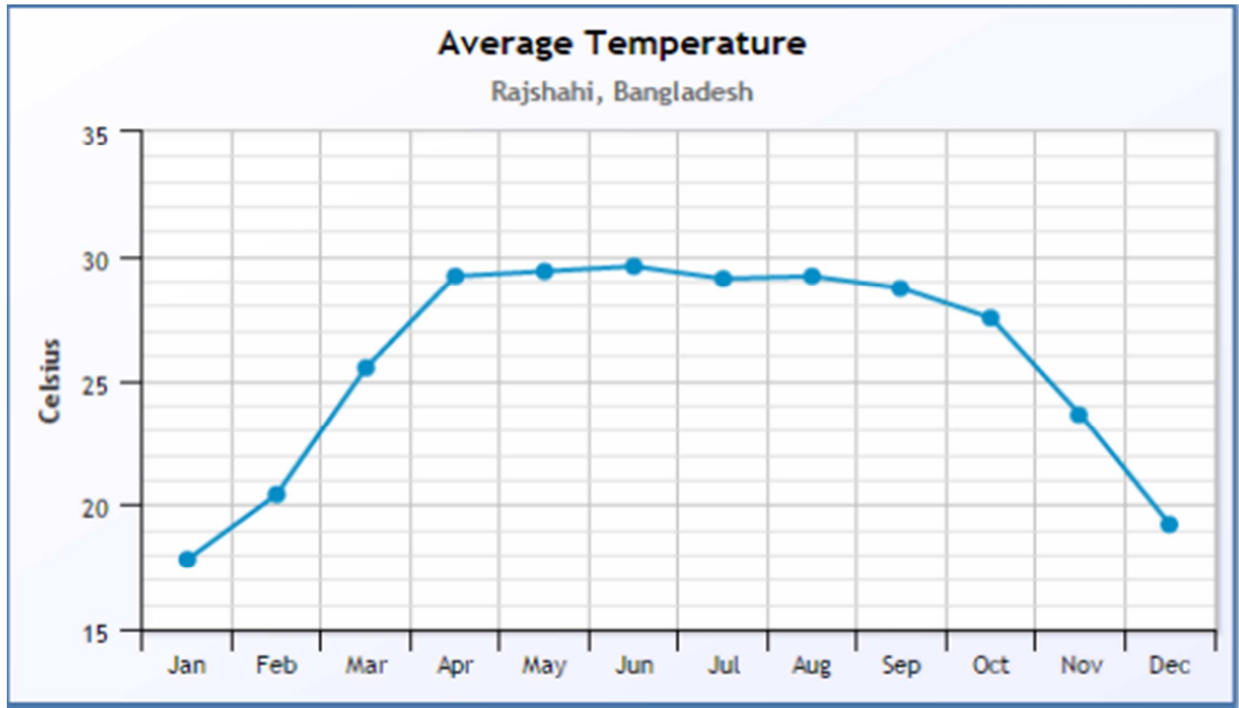

Figure 3. Average Monthly Temperature for Last 30 Years (Wetherbase. Com). 


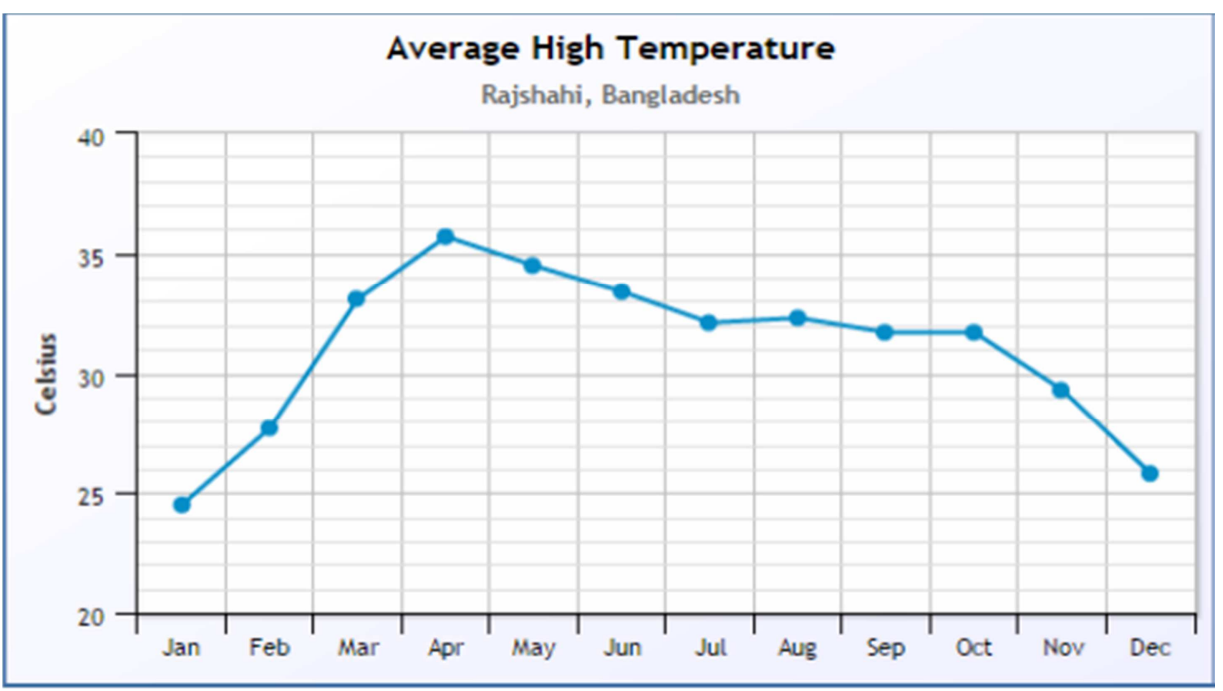

Figure 4. Average Monthly High Temperature for Last 30 Years (Wetherbase.Com).

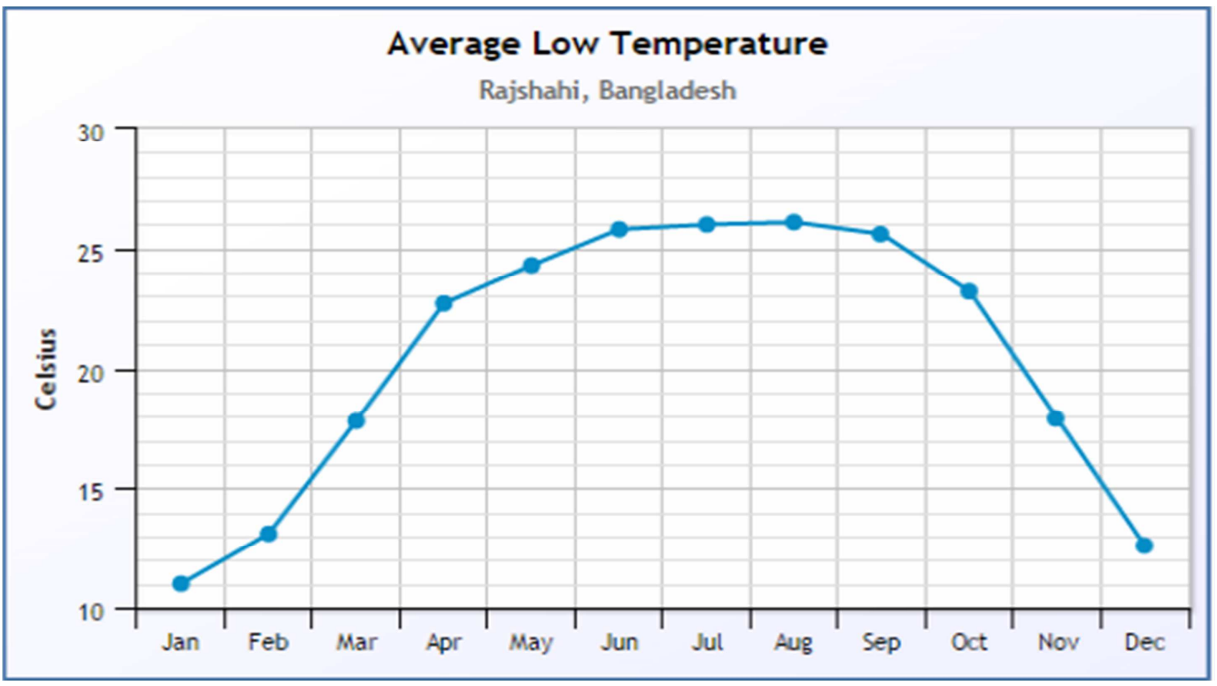

Figure 5. Average Monthly Low Temperature for Last 30 Years (Wetherbase.Com).

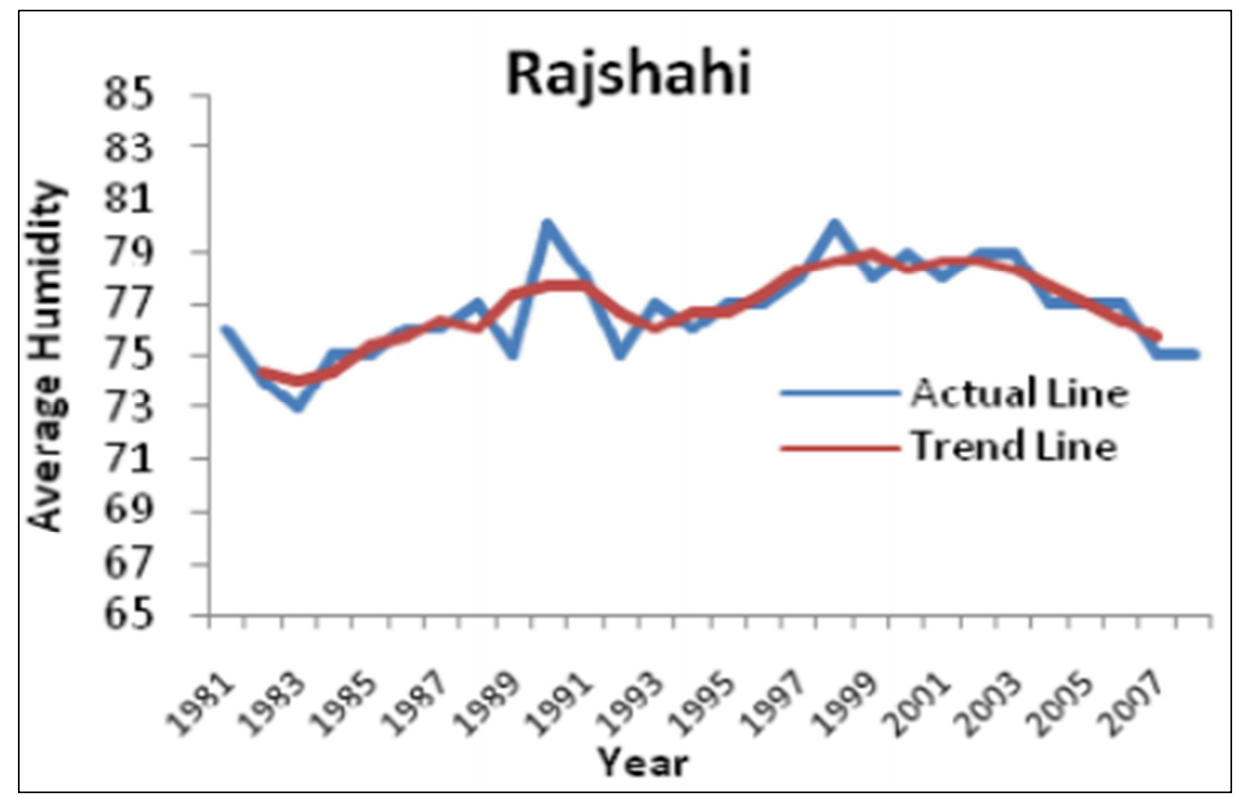

Figure 6. Average yearly Humidity from 1981 to 2007 (M. M. Islam, 2014). 


\section{Conclusion}

All potential impacts in the environment have been carefully studied, no matter if they present positive or negative impact to the environment.

Potential Impact during the preconstruction phase are activities that take place in the preconstruction phase (preparation site works) present several negative effects for environment, nevertheless with a minimum care these effects could be brought to a bare minimum. In this phase effects in the environment could be expected as a result of noise from vehicles, dust emissions, as a result of waste removal, soil contamination due to accidental leakage of oils and lubricants form equipment used, pollution of the road resulting by the traffic of equipment and transporting vehicles. Potential Impact under construction phase is during the construction phase there might be additional negative effects in the environment, but with the right management of such effects a real harm is not supposed to be caused to the environment. Potential effects (impacts) in the environments are presented as Soil degradation, noise quality, air quality, generation of waste due to construction activities, water quality, Flora, Fauna and health and safety of workers. Potential Impacts during the operation phase includes Ground Water Quality, Land and Soil, Fisheries, Workers' Health and Safety.

\section{References}

[1] Barlett, P. B. \& Prior, J. J. (1991), “The Environmental Impact of Buildings", Building Research Establishment (BRE) Information Paper, Pp 18-19, BRE, UK.
[2] Shen L. Y. \& Tam V. W. Y. (2002). "Implementation of environmental management in the Hong Kong construction industry”, Pp 535-543.

[3] Arquiaga M. C., Canter L. W. and Nelson D. I.(1992),"Risk Assessment Principles in Environmental Impact studies", Environmental Professional, 14, Pp 204-219.

[4] Mhaskar Z. (2005), "Environmental Impacts of Construction Activity \& Site Control Practices”, Eco housing India.

[5] Brundtland, G. H. (2007), "Report of the World Commission on Environment and Development", Our Common Future. New York, United Nations General Assembly.

[6] Forsberg, A. \& von Malmborg, F, (2004), "Tools for environmental assessment of the built environment", Building and Environment, 30: Pp 223-228.

[7] Hardy, A. (2007), "Environmental Design of Buildings", Ekistics 23 (136): Pp181-187.

[8] Research Project on Assessing Quality of Environmental Impact Assessment (EIA), Compliance of Environmental Clearance (EC) Conditions and Adequacy of Environmental Management Plan (EMP) of Mining Industry in Goa (2013).

[9] Horvath, A (2004), Construction Materials and the Environment. Annu. Resour. 29: Pp181-204.

[10] Chrisna, S. O. (2006), "Environmental Degradation and its Consequences". National Population Prevention Centre for Higher Education, University of Michigan. 